\title{
Phytochemical screening and antioxidant activities of Erythroxylum cuneatum leaf extracts
}

\begin{abstract}
Objectives: Erythroxylum cuneatum is a plant that belongs to the family of Erythroxylaceae. It is locally known as "Chinta mula" and found around Southeast Asia. This study identified the active phytochemicals and antioxidant properties in various extracts derived from dried leaves of Erythroxylum cuneatum. Methods: The tests of phytochemical screening included extracts of ethanol, acetone, hexane and aqueous. The antioxidant activity was determined by measuring total phenolic content, 2,2- diphenyl-1-picrylhydrazyl (DPPH) radical scavenging activity and hydrogen peroxide scavenging activity. Results: The phytochemical screening of Erythroxylum cuneatum dried leaves revealed the presence of phenolic compounds namely flavonoids, tannins and total phenols. Alkaloids and saponins were also detected. The antioxidant activity of the examined extracts varies depending on the solvent used. Generally, acetone extract showed highest total phenolic content with a value of $2228 \mu \mathrm{g} \mathrm{GAE} / \mathrm{g}$ and highest DPPH radical scavenging activity with IC50 of $1020.00 \mu \mathrm{g} / \mathrm{ml}$ compared to the standard ascorbic acid of $304.44 \mu \mathrm{g} / \mathrm{ml}$. Ethanol extract exhibited high hydrogen peroxide activity with IC50 of $83.09 \mu \mathrm{g} / \mathrm{ml}$. Conclusion: This study showed that acetone extract contains highest phenolic compounds and both ethanol and acetone extracts are a potential source of natural antioxidants.
\end{abstract}

Keyword: Erythroxylum cuneatum; Phytochemicals; Antioxidant activity; Phenolic; Free radical scavenging activity 